\title{
Hyperproduction of poly(4-hydroxybutyrate) from glucose by recombinant Escherichia coli
}

\author{
Xiao-Yun Zhou ${ }^{1 \dagger}$, Xiao-Xi Yuan ${ }^{1 \dagger}$, Zhen-Yu Shi ${ }^{2}$, De-Chuang Meng ${ }^{1}$, Wen-Jun Jiang ${ }^{1}$, Lin-Ping Wu ${ }^{3}$, \\ Jin-Chun Chen ${ }^{1 *}$ and Guo-Qiang Chen ${ }^{1,4^{*}}$
}

\begin{abstract}
Background: Poly(4-hydroxybutyrate) [poly(4HB)] is a strong thermoplastic biomaterial with remarkable mechanical properties, biocompatibility and biodegradability. However, it is generally synthesized when 4-hydroxybutyrate (4HB) structurally related substrates such as $\gamma$-butyrolactone, 4-hydroxybutyrate or 1,4-butanediol (1,4-BD) are provided as precursor which are much more expensive than glucose. At present, high production cost is a big obstacle for large scale production of poly(4HB).

Results: Recombinant Escherichia coli strain was constructed to achieve hyperproduction of poly(4-hydroxybutyrate) [poly(4HB)] using glucose as a sole carbon source. An engineering pathway was established in E. coli containing genes encoding succinate degradation of Clostridium kluyveri and PHB synthase of Ralstonia eutropha. Native succinate semialdehyde dehydrogenase genes sad and gabD in E. coli were both inactivated to enhance the carbon flux to poly (4HB) biosynthesis. Four PHA binding proteins (PhaP or phasins) including PhaP1, PhaP2, PhaP3 and PhaP4 from $R$. eutropha were heterologously expressed in the recombinant $E$. coli, respectively, leading to different levels of improvement in poly(4HB) production. Among them PhaP1 exhibited the highest capability for enhanced polymer synthesis. The recombinant $E$. coli produced $5.5 \mathrm{~g} \mathrm{~L}^{-1}$ cell dry weight containing $35.4 \%$ poly $(4 \mathrm{HB})$ using glucose as a sole carbon source in a $48 \mathrm{~h}$ shake flask growth. In a 6-L fermentor study, $11.5 \mathrm{~g} \mathrm{~L}^{-1}$ cell dry weight containing $68.2 \%$ poly (4HB) was obtained after $52 \mathrm{~h}$ of cultivation. This was the highest poly(4HB) yield using glucose as a sole carbon source reported so far. Poly(4HB) was structurally confirmed by gas chromatographic (GC) as well as ${ }^{1} \mathrm{H}$ and ${ }^{13} \mathrm{C}$ NMR studies.

Conclusions: Significant level of poly(4HB) biosynthesis from glucose can be achieved in sad and gabD genes deficient strain of E. coli JM109 harboring an engineering pathway encoding succinate degradation genes and PHB synthase gene, together with expression of four PHA binding proteins PhaP or phasins, respectively. Over $68 \%$ poly(4HB) was produced in a fed-batch fermentation process, demonstrating the feasibility for enhanced poly(4HB) production using the recombinant strain for future cost effective commercial development.
\end{abstract}

Keywords: Poly(4HB), PHB, Polyhydroxyalkanoates, PhaP, 4-hydroxybutyrate, Escherichia coli, Metabolic engineering, Synthetic biology

\section{Background}

A large variety of bacteria are able to accumulate diverse polyhydroxyalkanoates (PHA) as intracellular carbon and energy storage material under nutritional unbalanced conditions [1-4]. Due to their diverse structures, chirality, biodegradability and biocompatibility, PHA have

\footnotetext{
* Correspondence: chenjc@mail.tsinghua.edu.cn; chengq@mail.tsinghua.edu.cn ${ }^{\dagger}$ Equal contributors

'Department of Biological Science and Biotechnology, MOE Key Lab of Bioinformatics and Systems Biology, School of Life Sciences, Tsinghua-Peking Center for Life Sciences, Tsinghua University, Beijing, 100084, China

${ }^{4}$ Center for Nano and Micro Mechanics, Tsinghua University, Beijing, 100084, China Full list of author information is available at the end of the article
}

attracted attentions from academic and industrial communities for their potential applications in areas of agriculture, medicine, and materials [2,5-7]. More than 150 types of hydroxyalkanoic acids have been known as monomers of PHA, leading to diverse polymer physical properties [8-11]. Some of the PHA monomers and oligomers were reported to stimulate cell proliferations $[12,13]$.

Homopolyesters of 4-hydroxybutyrate, or Poly(4HB), is a strong thermoplastic material with an elongation to break of $1000 \%$, which means it can be stretched 10 times its original length before it is broken [14]. Due to

\section{Biomed Central}


the remarkable mechanical properties, biocompatibility and biodegradability, poly $(4 \mathrm{HB})$ has been approved by the United States Food and Drug Administration (FDA) as the first PHA medical implant material among several PHA materials under investigation $[5,15,16]$.

4-hydroxybutyrate $(4 \mathrm{HB})$ was first detected in a copolyester of $3 \mathrm{HB}$ and $4 \mathrm{HB}$ isolated from $R$. eutropha [17] and generally the incorporation of $4 \mathrm{HB}$ into PHA occurred only if 4-Hydroxybutyrate, 4-butyrolactone, 1,4butanediol or 4-chlorobutyrate was provided as carbon source [18]. Poly(4HB) homopolyester was first reported to be synthesized by $R$. eutropha using 4-hydroxybutyrate as a precursor [19]. Wild-type bacteria like Comanonas acidovorans [20] and Hydrogenophaga pseudovorans [21] were also found to produce poly $(4 \mathrm{HB})$. Recombinant E. coli expressing $R$. eutropha PHA synthase gene phaC and Clostridium kluyveri 4HB-CoA:CoA transferase gene orf $Z$ were found able to synthesize poly(4HB) homopolyester when both glucose and $4 \mathrm{HB}$ were provided as carbon sources $[22,23]$. As a general rule, structurally related substrates of 4HB such as $\gamma$-butyrolactone, 4-hydroxybutyrate or 1,4-butanediol (1,4-BD) are required as precursors for poly(4HB) synthesis [24]. However, these substrates are much more expensive than glucose, leading to the high cost of poly $(4 \mathrm{HB})$ production. Song et al. succeeded in producing poly $(4 \mathrm{HB})$ homopolyester using glucose as a sole carbon source in recombinant E. coli [25]. However, the reported yield $\left(0.78 \mathrm{~g} \mathrm{~L}^{-1}\right)$ was low for mass cultivation. The high cost of raw material and the low yield of poly $(4 \mathrm{HB})$ prevents wide exploitation of poly $(4 \mathrm{HB})$ for more applications [26].

Studies on producing poly(3-hydroxybutyrate-co-4hydroxybutyrate) or $\mathrm{P} 3 \mathrm{HB} 4 \mathrm{HB}$ from glucose in E. coli were reported $[27,28]$. The $4 \mathrm{HB}$ monomer was synthesized from anaerobic succinate degradation pathway of C. kluyveri. In this pathway, the intermediate of tricarboxylic acid (TCA) cycle succinyl-CoA was converted to succinate semialdehyde (SSA) by SSA dehydrogenase, and SSA was reduced to $4 \mathrm{HB}$ by $4 \mathrm{HB}$ dehydrogenase (Figure 1) $[29,30]$. Subsequently, $4 \mathrm{HB}$ was converted to 4HB-CoA via 4HB-CoA:CoA transferase. In C. kluyveri, these three enzymes were encoded by genes $s u c D, 4 h b D$ and $\operatorname{orfZ}$, respectively [28].

E. coli possesses two forms of SSA dehydrogenase (SSADH) encoded by sad and $g a b D$ first identified in $R$. eutropha [31], both SSADH catalyze degradation of SSA to succinate which can reduce the SSA flux to 4HBCoA pathway. Li et al. reported an enhancement on $4 \mathrm{HB}$ content in P3HB4HB when SSADH was inactivated in E. coli, indicating a possibility of producing poly $(4 \mathrm{HB})$ in sad and $g a b D$ deficient mutant.

Phasins are small amphiphilic proteins localizing at the surface of PHA granules and there are interactions among various phasins [32-35]. They play important

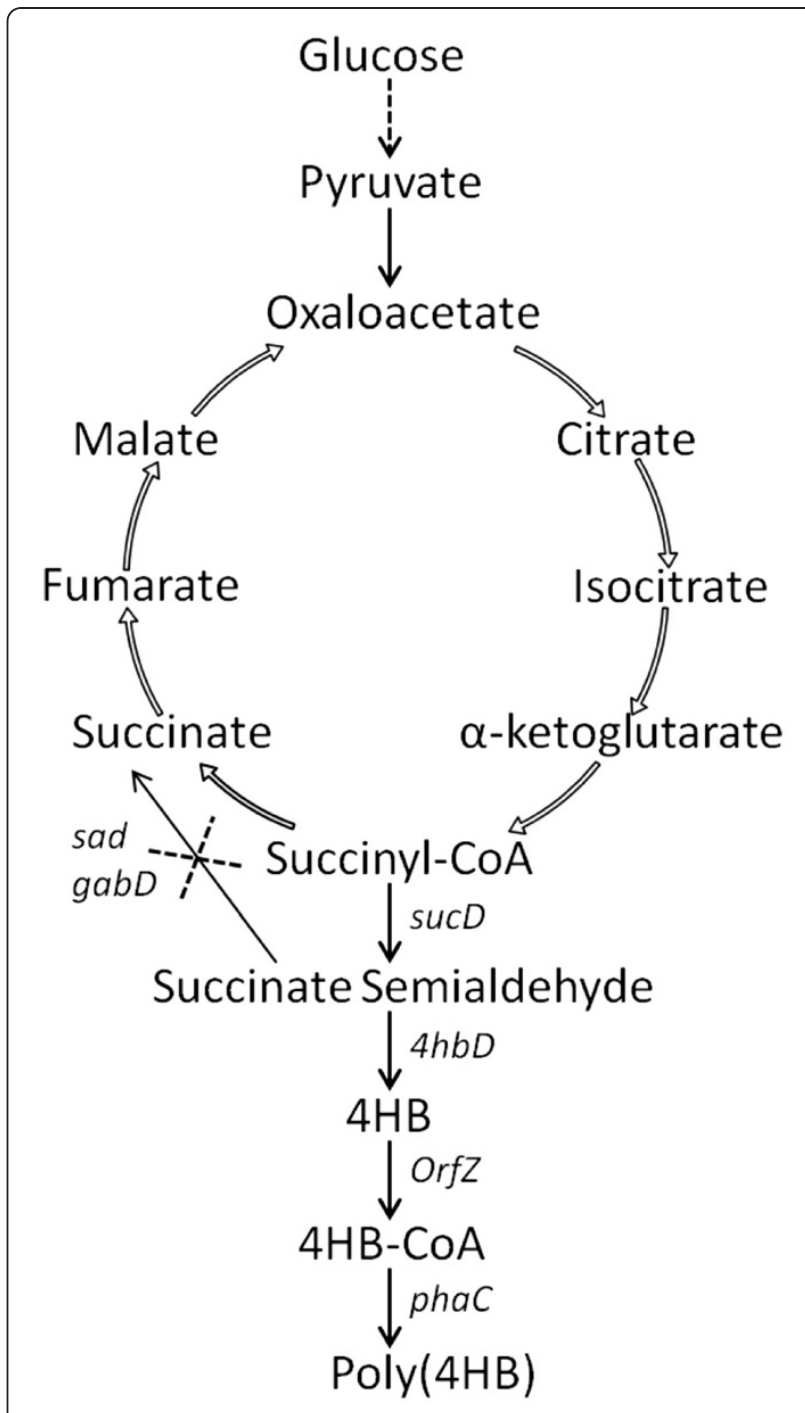

Figure 1 Engineering pathway for microbial production of Poly (4HB) from glucose in $E$. coli. Enzymes encoded by the over-expressed genes in the pathway: sucD, succinate semialdehyde dehydrogenase of C. kluyveri; $4 h b D$, 4-hydroxybutyrate dehydrogenase; orfZ, 4HB-CoA:CoA transferase; phaC, PHA synthase; sad and gabD, succinate semialdehyde dehydrogenase of $E$. coli.

roles in PHA synthesis and granule formation [36]. The PhaP phasins were proven to promote PHB synthesis by regulating the surface/volume ratio of $\mathrm{PHB}$ granules or by interacting with PHA synthase yet without influencing PHA molecular weights [37]. Four genes encoding highly homologous phasins including phaP1, phaP2, phaP3 and phaP4 were found in $R$. eutropha, among which PhaP1 is the major phasin protein [38-40].

The aim of this study was to construct a recombinant E. coli for hyperproduction of poly $(4 \mathrm{HB})$ using glucose as a sole carbon source. 


\section{Results}

Synthesis of poly(4HB) by recombinant $E$. coli grown in shake flasks

Biosynthesis pathway of poly (4HB) was constructed in sad and gabD deficient strain E. coli JM109SG by co-expressing sucD, $4 h b D$, orf $Z$ and phaC heterologously using compatible plasmids pMCSH5 harboring sucD and $4 h b D$ and pKSSE5.3 harboring orf $Z$ and phaC (Figures 1 and 2). To study the function of $\mathrm{PhaP}$ on poly $(4 \mathrm{HB})$ production, four plasmids pKSSEP1, pKSSEP2, pKSSEP3 or pKSSEP4 were co-transformed with the plasmid pMCSH5 into E. coli JM109SG, respectively. In the pKSSEPx plasmid series, genes phaC and phaPx shared the same promoter $\mathrm{P}_{\mathrm{Re}}$ from $R$. eutropha while orfZ gene was initiated by its own promoter (Figure 2). In plasmid pMCSH5, sucD and $4 h b D$ genes were controlled by promoter $\mathrm{P}_{p d c}$. The function of poly $(4 \mathrm{HB})$ biosynthesis pathway with or without PhaP was tested in E. coli JM109 and its SSADH deficient strain was cultivated in shake flasks for $48 \mathrm{~h}$ in LB medium supplemented with $20 \mathrm{~g} \mathrm{~L}^{-1}$ glucose and PBS buffer.

Gas chromatographic analysis of derivatives obtained from lyophilized cells provided the single peak representing the methyl ester of $4 \mathrm{HB}$, demonstrating that the resulting PHA was a poly $(4 \mathrm{HB})$ homopolyester. As expected, E. coli JM109 (pKSSE5.3, pMCSH5) did not produce any polyester. In comparison, its sad and gabD deficient mutant E. coli JM109SG (pKSSE5.3, pMCSH5) grew to $3.8 \mathrm{~g} \mathrm{~L}^{-1} \mathrm{CDW}$ containing $12 \mathrm{wt} \%$ poly(4HB) (Table 1). The co-expression of $\mathrm{PhaP}_{1-4}$ in $E$. coli

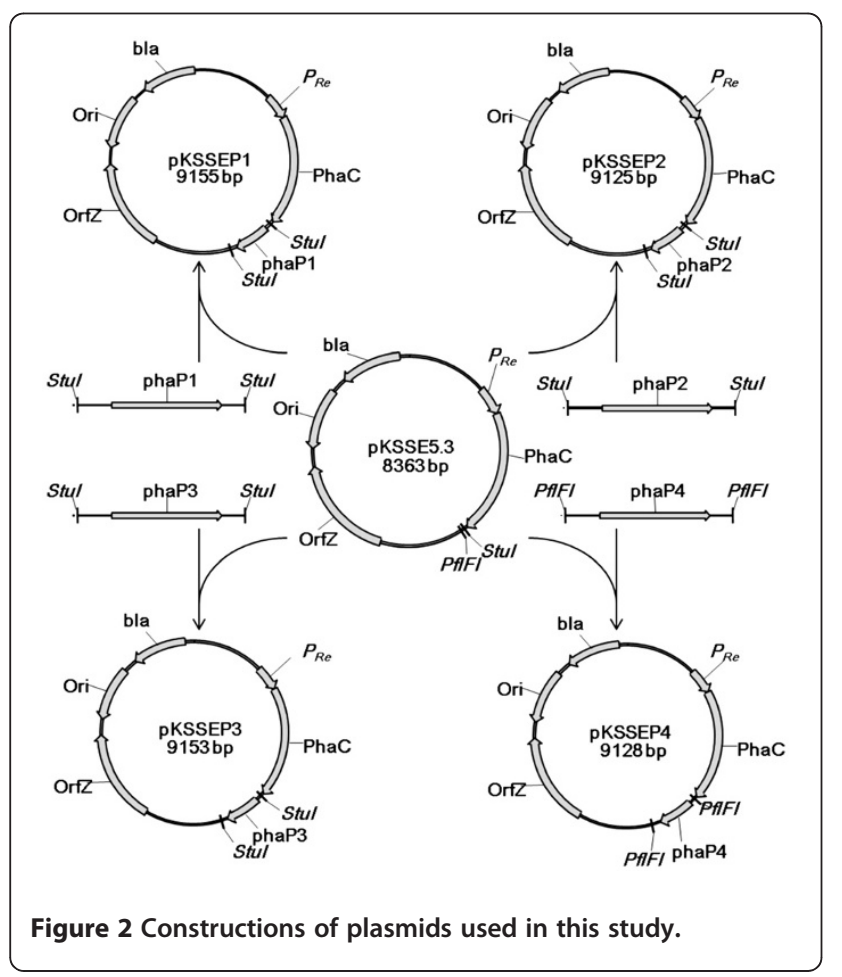

Table 1 Shake flasks study of poly(4HB) production from glucose by $E$. coli strains grown in shake flasks ${ }^{a}$

\begin{tabular}{ccccc}
\hline E. coli & Plasmids & $\begin{array}{c}\text { CDW }^{b} \\
\left.\text { (g L }^{-1}\right)\end{array}$ & $\begin{array}{c}\text { Poly(4HB) } \\
\text { content }^{c} \text { (wt\%) }\end{array}$ & $\begin{array}{c}\text { Poly(4HB) } \\
\left.\mathbf{( g ~ L}^{-1}\right)\end{array}$ \\
\hline JM109 & pKSSE5.3, pMCSH5 & $3.33 \pm 0.13$ & $-^{d}$ & - \\
JM109SG & pKSSE5.3, pMCSH5 & $3.83 \pm 0.15$ & $12.13 \pm 0.53$ & $0.47 \pm 0.04$ \\
JM109SG & pKSSEP1, pMCSH5 & $5.46 \pm 0.04$ & $35.39 \pm 0.80$ & $1.93 \pm 0.06$ \\
JM109SG & pKSSEP2, pMCSH5 & $4.30 \pm 0.17$ & $22.85 \pm 1.06$ & $0.98 \pm 0.07$ \\
JM109SG & pKSSEP3, pMCSH5 & $4.28 \pm 0.12$ & $32.35 \pm 1.42$ & $1.39 \pm 0.09$ \\
JM109SG & pKSSEP4, pMCSH5 & $4.34 \pm 0.15$ & $22.95 \pm 2.58$ & $1.00 \pm 0.14$
\end{tabular}

${ }^{a}$ Cells were cultivated in LB medium at $37^{\circ} \mathrm{C}$ and $200 \mathrm{rpm}$ for $48 \mathrm{~h}$ as described in "Materials and methods" $20 \mathrm{~g} \mathrm{~L}^{-1}$ glucose and PBS buffer were added to the medium after sterilization. Three parallel studies were conducted for each data.

${ }^{b} \mathrm{CDW}$ : cell dry weight.

c Poly(4HB) content: PHA contents are given as mass percentage of CDW.

d Not detected.

JM109SG (pKSSE5.3, pMCSH5) led to enhancements of poly $(4 \mathrm{HB})$ accumulation from $12 \mathrm{wt} \%$ without any PhaP to at least $22 \mathrm{wt} \%$ with PhaP4 to a maximum of $35 \mathrm{wt} \%$ with PhaP1. CDW also reached the highest of $5.5 \mathrm{~g} \mathrm{~L}^{-1}$ containing more than $35 \mathrm{wt} \%$ poly $(4 \mathrm{HB})$ when phaP1 was expressed in E. coli JM109SG (pKSSEP1, pMCSH5). Expression of phaP3 resulted in second highest poly (4HB) accumulation of $32 \mathrm{wt} \%$ CDW by E. coli JM109SG (pKSSEP3, pMCSH5). While PhaP2 and PhaP4 showed a similar lower ability on the improvement of poly $(4 \mathrm{HB})$ synthesis by the $E$. coli. The results were consistent with the different roles played by the four PhaP phasins for PHA synthesis $[39,40]$.

\section{Production and structure confirmation of poly(4HB) from fermentor study}

As revealed by the shake flask results (Table 1), E. coli JM109SG (pKSSEP1, pMCSH5) showed the fastest growth rate and highest poly $(4 \mathrm{HB})$ accumulation level among all strains studied. It was therefore selected for further studies using well-controlled fermentor. E. coli JM109SG (pKSSEP1, pMCSH5) was grown in the modified LB medium containing tripled amount of yeast extract in a fed-batch fermentation process maintaining $10 \mathrm{~g} \mathrm{~L}^{-1}$ glucose during the entire period. After $52 \mathrm{~h}$ of fermentor cultivation, the cells grew to approximately $12 \mathrm{~g} \mathrm{~L}^{-1} \mathrm{CDW}$ containing over $68 \mathrm{wt} \%$ poly $(4 \mathrm{HB})$ in the expense of a total of $90 \mathrm{~g} \mathrm{~L}^{-1}$ glucose consumed. This was by far, the highest poly $(4 \mathrm{HB})$ production using glucose as a sole carbon source. The poly $(4 \mathrm{HB})$ synthesis increased very fast during the exponential growth phase, and reached a relatively stable level at over $60 \mathrm{wt} \%$ poly (4HB) in CDW after $32 \mathrm{~h}$ (Figure 3).

To confirm homopolyester structure, gas chromatography and NMR were employed. As evidenced by spectra of ${ }^{1} \mathrm{H}$ NMR and ${ }^{13} \mathrm{C}$ NMR (Figure 4), three 


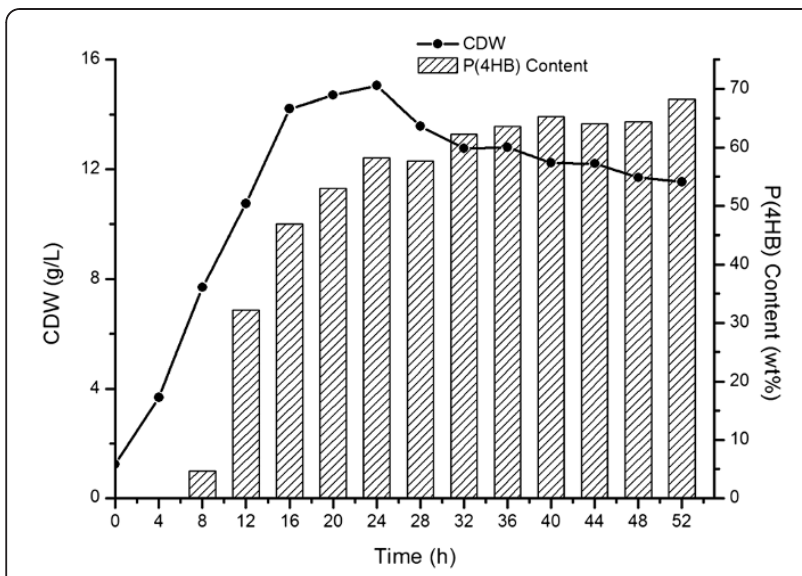

Figure 3 Growth and poly(4HB) production by recombinant $E$. coli harboring pKSSEP1 and PMCSH5 cultivated in a 6-I fermentor. well-characterized proton resonances, namely, 4HB (2): $\delta$ 2.39-2.37 ppm, 4HB (3): $\delta$ 1.97-1.93 ppm, 4HB (4): $\delta$ 4.12-4.09 $\mathrm{ppm}$, appeared with identical intensities assigned to only $4 \mathrm{HB}$ units (Figure $4 \mathrm{~A}$ ). In the inserted dashed chart, the protons of $4 \mathrm{HB}(2)$ and $4 \mathrm{HB}$ (4) were found split into three peaks, while the peak of $4 \mathrm{HB}$ (3) proton was quadrupled based on the " $\mathrm{N}+1$ rule": a proton with $\mathrm{N}$ neighbors appears as a cluster of $\mathrm{N}+1$ peaks. For example, the proton of $4 \mathrm{HB}(3)$ is neighbored to $4 \mathrm{HB}(2)$ and $4 \mathrm{HB}(4)$, and it has four protons around it as shown from the molecular structure of $4 \mathrm{HB}$, thus, the proton of $4 \mathrm{HB}(3)$ is split into five peaks (Figure 4A). Furthermore, the four ${ }^{13} \mathrm{C}$ resonances at $20-180 \mathrm{ppm}$ could be assigned to specific carbon species of $4 \mathrm{HB}$ units (Figure 4B). The carbon of carbonyl group 4HB (1) had the highest field in ${ }^{13} \mathrm{C}$ NMR, the chemical shift was $\delta 172.74 \mathrm{ppm}$. From left to right, the chemical shifts of $\delta 63.61 \mathrm{ppm}, \delta 30.73$ and $\delta 24.74 \mathrm{ppm}$ belonged to $4 \mathrm{HB}$

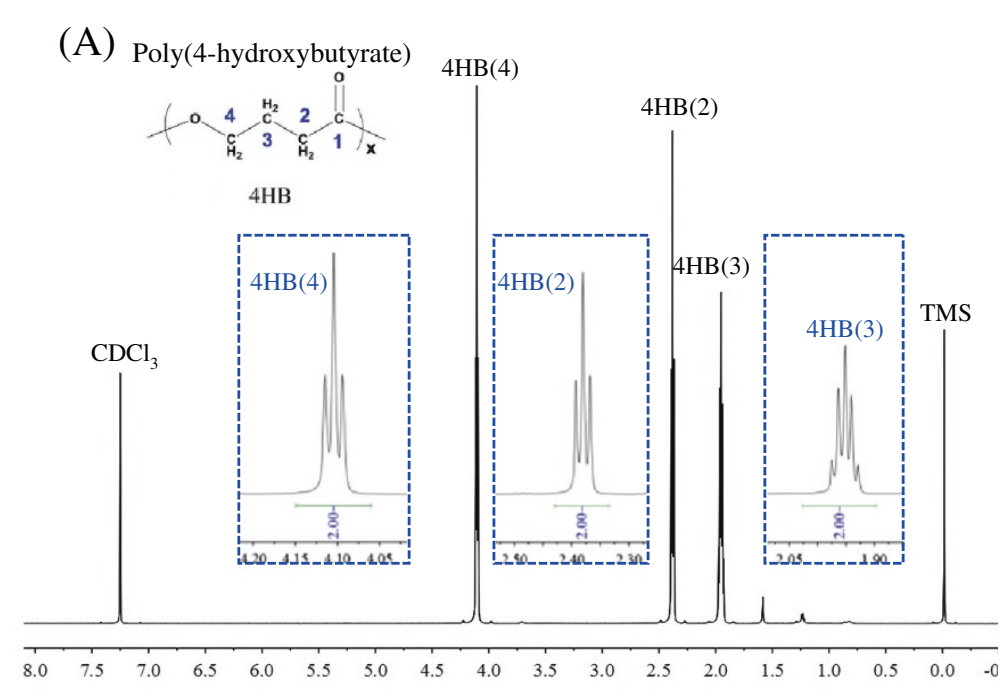

(B)

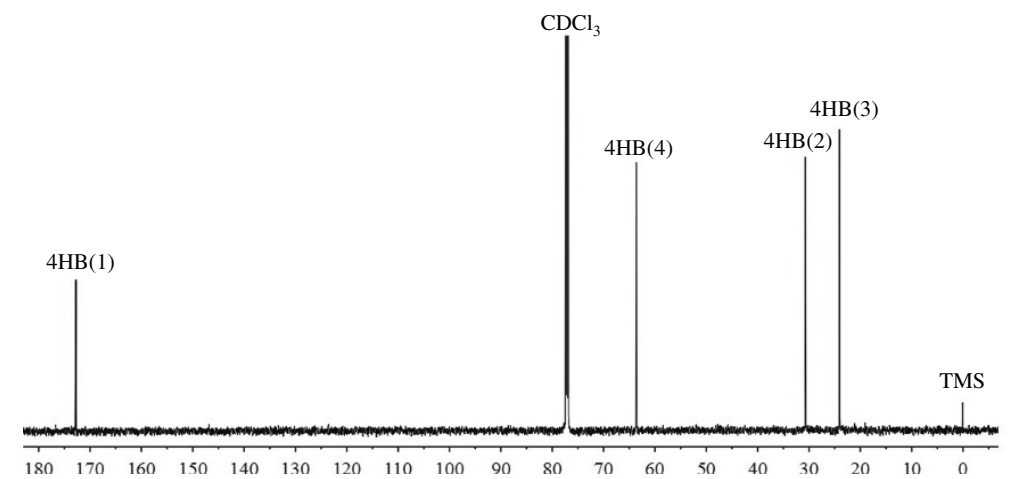

Figure $4{ }^{1} \mathrm{H}$ NMR (A) and ${ }^{13} \mathrm{C}$ NMR spectra (B) of poly(4HB). Numbering scheme were the same as that of poly(4HB) molecular structure described in (A). The inserted dashed enveloped areas in (A) were the enlarged details of each proton split peaks. Chemical shifts were in ppm and tetramethylsilane (TMS) was employed as an internal chemical shift standard. 
(4), 4HB (2) and 4HB (3), respectively. Based on these data, the NMR spectra confirmed the polyester sample be a homopolyester consisting of only 4-hydroxybutyrate.

\section{Physical characterization of poly(4HB) produced by the recombinant $E$. coli}

Poly(4HB) produced by E. coli JM109SG (pKSSEP1, pMCSH5) was extracted and purified before casting into films for mechanical property studies. The white and foggy poly(4HB) films exhibited a much higher elasticity than other known PHA. Its elongation at break $\left(\varepsilon_{\mathrm{b}}\right)$, tensile strength $\left(\sigma_{t}\right)$, and Young's modulus (E) was 1014\%, $32.55 \mathrm{MPa}$ and $12.8 \mathrm{MPa}$, respectively. The poly $(4 \mathrm{HB})$ had a molecular mass of weight average molecular weigh $\left(\mathrm{M}_{\mathrm{w}}\right)$ of $0.22 \times 10^{6}$ together with a polydispersity $\left(\mathrm{M}_{\mathrm{w}} / \mathrm{M}_{\mathrm{n}}\right)$ of 2.11 as determined by gel-permeation chromatography.

\section{Discussion}

As a strong pliable thermoplastic material with good flexibility, poly $(4 \mathrm{HB})$ has been approved by FDA as a suture material (www.tepha.com). Biomedical applications are usually not sensitive to high cost. However, a reduction on poly $(4 \mathrm{HB})$ production cost should allow for more application exploitation. High production cost for poly (4HB) comes from expensive $4 \mathrm{HB}$ precursors including 4-hydroxybutyric acid, $\gamma$-butyrolacton or 1,4-butanediol $[41,42]$, and from very low yield of poly $(4 \mathrm{HB})$ by recombinant bacteria. Therefore, simple and low cost substrates as well as a highly productive strain can help reduce poly $(4 \mathrm{HB})$ production cost.

The anaerobic succinate degradation pathway employed in this study conferred on the recombinant $E$. coli the ability to utilize glucose as a sole carbon source for poly (4HB) production. The additional expression of PHA granule associate protein $\mathrm{PhaP}$ provided a further enhancement on poly $(4 \mathrm{HB})$ yield, allowing for further fermentor exploitation. While in wild E. coli strain, succinate semialdehyde can be degraded to succinate by SSA dehydrogenase (SSADH) encoded by sad and gabD [30], leading to a decreased metabolic flux to $4 \mathrm{HB}$ production (Figure 1). To channel more flux to $4 \mathrm{HB}$, the native SSADH genes of $E$. coli were inactivated in the poly $(4 \mathrm{HB})$ producing recombinant. Shake flask studies of E. coli JM109 and its SSADH deficient mutant JM109SG harboring pMCSH5 and pKSSE5.3 showed that inactivation of SSADH genes significantly improved poly(4HB) synthesis compared with the wild strain JM109 which had no poly (4HB) production at all (Table 1). On the other hand, the highest 4HB molar fraction in P3HB4HB synthesized from glucose in E. coli was $11 \%$ reported so far [28]. Our result indicated that the recombinant enzymes in this pathway were active enough to provide sufficient $4 \mathrm{HB}$ from glucose for polymerization.
Expression of all four PhaPs (phasin) cloned from $R$. eutropha provided additional improvement on poly (4HB) accumulation in the order of PhaP1 $>$ PhaP3 $>$ PhaP2 > PhaP4 (Table 1). The differences of their different influences are not clear yet but probably due to the different roles of PhaP played on PHA granules formation. PhaP1 was the major phasin with the highest expression amount in $R$. eutropha while PhaP2, PhaP3 and $\mathrm{PhaP} 4$ were small in quantity $[39,40]$, indicating its dominating function for PHA granule formation, and PhaP3 was expressed at a significantly high level in PhaP1 deficient strains, other PhaPs were in much lower levels. Our results therefore suggested that the poly $(4 \mathrm{HB})$ yields were positively related to the expression levels of PhaP.

The recombinant $E$. coli JM109SG (pKSSEP1, pMCSH5) grown to $12 \mathrm{~g} \mathrm{~L}^{-1} \mathrm{CDW}$ under a well-controlled fermentor run in a fed-batch process accumulated over $68 \%$ poly (4HB) using glucose as the only carbon source over a $52 \mathrm{~h}$ period (Figure 3 ). This is by far the highest yield for poly (4HB). In its exponential growth period of 8-24 h after innoculation, poly $(4 \mathrm{HB})$ content increased most rapidly and reached a relatively stable level when cells entered the stationary phase. As in the exponential phase, TCA cycle is most active, supplying the most succinyl-CoA for the poly $(4 \mathrm{HB})$ synthesis, leading to a rapid poly $(4 \mathrm{HB})$ accumulation rate. A continuous fermentation process that maintains the cells in their exponential growth phase may further improve poly $(4 \mathrm{HB})$ accumulation level.

\section{Conclusion}

In summary, Escherichia coli strain JM109 harboring an engineering pathway encoding succinate degradation genes of Clostridium kluyveri and PHB synthase gene of Ralstonia eutropha together with its native succinate semialdehyde dehydrogenase genes sad and gabD inactivated, was able to achieve significant level of poly $(4 \mathrm{HB})$ biosynthesis from glucose. Additional expression of four PHA binding proteins PhaP or phasins in the recombinant strain, respectively, led to a further improvement of poly $(4 \mathrm{HB})$ accumulation. PhaP1 was found most useful among the four PhaPs used. Over $68 \mathrm{wt} \%$ poly (4HB) was produced in a fed-batch fermentation process, demonstrating the feasibility for enhanced poly $(4 \mathrm{HB})$ production using the recombinant strain for future cost effective commercial development.

\section{Methods}

\section{Bacterial strains and plasmids}

The bacterial strains and plasmids used in this study were listed in Table 2. E. coli Trans1-T1 from TransGen Biotech (Beijing, China) was used for plasmids construction. Ralstonia eutropha was used as a template for gene cloning [43]. E. coli JM109 (TaKaRa, Dalian, China) and 
Table 2 Bacterial strains and plasmids used in this study

\begin{tabular}{|c|c|c|}
\hline Name & Relevant characteristics & Source or reference \\
\hline \multicolumn{3}{|l|}{ Strains } \\
\hline \multirow[t]{2}{*}{ E. coli JM109 } & recA1, endA1, gyrA96, thi, hsdR17, supE44, relA1, $\Delta($ lac proAB)/F' & TaKaRa (Dalian, China) \\
\hline & {$\left[\operatorname{traD} 36, \operatorname{pro} B^{+}, \operatorname{lac}^{9}\right.$ lacZ $\left.\Delta \mathrm{M} 15\right]$} & \\
\hline E. coli JM109SG & JM109 $\triangle$ sad $\triangle g a b D$ & {$[28]$} \\
\hline E. coli Trans1-T1 & The fastest growing chemically competent strain currently available & $\begin{array}{l}\text { TransGen Biotech } \\
\text { (Beijing, China) }\end{array}$ \\
\hline Ralstonia eutropha $\mathrm{H} 16$ & Wild type & ATCC17699a $[43]$ \\
\hline \multicolumn{3}{|l|}{ Plasmids } \\
\hline pKSSE5.3 & pBluescript vector derived, containing phaC and orfZ, $\mathrm{Amp}^{R}$ & [22] \\
\hline PKSSEP1 & phaP1 gene inserted into pKSSE5.3, Amp ${ }^{R}$ & This study \\
\hline pKSSEP2 & phaP2 gene inserted into pKSSE5.3, Amp ${ }^{R}$ & This study \\
\hline pKSSEP3 & phaP3 gene inserted into pKSSE5.3, Amp ${ }^{R}$ & This study \\
\hline PKSSEP4 & phaP4 gene inserted into pKSSE5.3, Amp ${ }^{R}$ & This study \\
\hline pMCSH5 & sucD-4hbD inserted into pBBR1MCS-2, $\mathrm{Km}^{R}$ & {$[28]$} \\
\hline \multicolumn{3}{|l|}{ Primers $\left(5^{\prime} \rightarrow 3^{\prime}\right)$} \\
\hline phaP1F & AGTCTAGGCCTAAGAAATGCGCCTTGACCCACCC & This study \\
\hline phaP1R & AGTCTAGGCCTGCAAAACACACCGCAAACGCCAG & \\
\hline phaP2F & CAGCGAGGCCTGTTCGCAATGCTGCAATCTTTATT & This study \\
\hline phaP2R & ACTATAGGCCTATACCACCCGTGACAACGGCAAG & \\
\hline phaP3F & ACTATAGGCCTGATTCGCACTCGGATGCTGCGCT & This study \\
\hline phaP3R & CAGCGAGGCCTITGTATACCGATGCGGGAAGATT & \\
\hline phaP4F & CAGCGGACGTTGTCTCACGATGCAGCAATTGTITTCC & This study \\
\hline phaP4R & AGTCTGACGTTGTCCTTCGACACGAAGGAAGTTTAGGC & \\
\hline
\end{tabular}

${ }^{a}$ American Type Culture Collection.

its sad and gabD deficient strain E. coli JM109SG were used for gene expression and poly $(4 \mathrm{HB})$ accumulation.

Plasmid pKSSE5.3 was constructed by Hein et al. containing genes phaC and orfZ [22]. Plasmids pKSSEPx, with " $x$ " referring to $1,2,3$ and 4 in this study, were constructed by subcloning genes phaP1, phaP2, phaP3 and phaP4 from genome of R. eutropha, followed by inserting them into the plasmid pKSSE5.3, respectively. Primers phaPxF and phaPxR were used for PCR amplification. The PCR products of phaP1, phaP2 and phaP3 fragments were digested by StuI while phaP4 fragment digested by $p$ FlfI. The gel electrophoresis-purified fragments were then ligated with pKSSE5.3 digested by the respective endonuclease (Figure 2). Plasmid pMCSH5 was constructed by Li et al. containing $s u c D$ and $4 h b D$ genes [28].

\section{Cultivation conditions and culture medium}

Plasmids pKSSE5.3 or pKSSEPx were co-transformed with pMCSH5 into E. coli JM109 and its SSADH deficient mutant by electroporation.
For shake flask cultivations, the growth process was carried out on a rotary shaker at $200 \mathrm{rpm}$ in $500 \mathrm{~mL}$ conical flasks containing $50 \mathrm{~mL}$ LB medium supplemented with $20 \mathrm{~g} \mathrm{~L}^{-1}$ glucose at an inoculation volume of $4 \%$ for $48 \mathrm{~h}$. For fermentation studies, seed culture was inoculated into a 6-L fermentor (NBS3000, New Brunswick, USA) at 10\% inoculation volume with an operating volume of $3 \mathrm{~L}$. The fermentation process was carried out at $37^{\circ} \mathrm{C}, \mathrm{pH} 7.0$ under a dissolved oxygen concentration (DO) of $30 \%$ of saturation. For poly $(4 \mathrm{HB})$ accumulation, concentrated glucose was complemented when $\mathrm{OD}_{600}$ began to increase exponentially to maintain the concentration of glucose above $10 \mathrm{~g} \mathrm{~L}^{-1}$ during the fermentation process.

For shake flask studies, Luria-Bertani (LB) medium supplemented with $20 \mathrm{~g} \mathrm{~L}^{-1}$ glucose in phosphate buffered saline (PBS) solution with a working concentration of $2.31 \mathrm{~g} \mathrm{~L}^{-1} \mathrm{KH}_{2} \mathrm{PO}_{4}$ and $16.42 \mathrm{~g} \mathrm{~L}^{-1} \mathrm{~K}_{2} \mathrm{HPO}_{4} \cdot 3 \mathrm{H}_{2} \mathrm{O}$ to maintain a pH around 7.0. Glucose and PBS were added to the medium after heat sterilization. During the fermentation process, LB medium with $15 \mathrm{gL}^{-1}$ yeast 
extract without PBS was used to promote cell growth. $50 \mathrm{mg} \mathrm{L}^{-1}$ kanamycin and $100 \mathrm{mg} \mathrm{L}^{-1}$ ampicillin were added to the medium to maintain stability of the plasmids during the growth processes.

\section{Analytical methods}

Bacterial cultures were harvested by centrifugation at $3000 \mathrm{~g}$ for $10 \mathrm{~min}$ and then washed with distilled water. The cell dry weight (CDW) was measured after vacuum lyophilization. PHA content and composition were analyzed by gas chromatography (SHIMADZU GC-2014 C, Kyoto, Japan) after methanolysis of lyophilized cells in chloroform with $\gamma$-butyrolactone (Sigma-Aldrich) used as standard $[44,45]$.

\section{PHA extraction and physical characterization}

PHA were extracted from the lyophilized cells [42]. In details: $10 \mathrm{~mL}$ chloroform was added to $1 \mathrm{~g}$ of dry cells in screw-capped tubes. The tubes were maintained at $100^{\circ} \mathrm{C}$ for $4 \mathrm{~h}$. Subsequently, equal volume of water was added to the tube and the chloroform at the bottom was sucked out and precipitated with an excess of 10 volumes of ice-cold ethanol [46].

The molecular structure of poly $(4 \mathrm{HB})$ was studied using nuclear magnetic resonance (NMR). The sample was dissolve in deuterated-chloroform $\left(\mathrm{CDCl}_{3}\right)$ and recorded the ${ }^{1} \mathrm{H}$ NMR and ${ }^{13} \mathrm{C}$ NMR spectra. The proton $\left({ }^{1} \mathrm{H}\right)$ NMR was performed on JOEL JNM- ECA 300 NMR spectrophotometer in deuterated chloroform as a solvent, tetramethylsilane (TMS) was used as an internal chemical shift standard. Carbon $\left({ }^{13} \mathrm{C}\right)$ NMR spectra was measured on $600 \mathrm{MHz}$ spectrophotometer.

To study its mechanical properties, PHA samples were spread into films by the conventional solvent-casting method [47]. The resulting PHA films were cut into rectangle-shaped specimens with a width of $10 \mathrm{~mm}$ and a thickness of approximately $120 \mu \mathrm{m}$. The stress-strain measurements of films were carried out using an AL$7000 \mathrm{~S}$ testing machine (Gotech Testing Machine, China) at room temperature. The speed of the cross-head was $50 \mathrm{~mm} \mathrm{~min}^{-1}$ [48]. Molecular weights were obtained via gel permeation chromatography (GPC Spectra System P2000) equipped with a Shimadzu RID-10A detector.

\section{Competing interests}

The authors declare that they have no competing interests.

\section{Authors' contributions}

$X Y Z$ designed the experiments, constructed the plasmids, performed fermentation studies and prepared the manuscript. XXY performed shake flask experiments. ZYS provided suggestions. DCM and WJJ participated in the fermentation process. LPW analyzed the NMR data. JCC and GQC supervised the study. All authors read and approved the final manuscript.

\section{Acknowledgements}

We are grateful to Professor Alexander Steinbüchel of the University of Münster in Germany for the generous donation of Ralstonia eutropha H16. We are also very grateful to Professor Shui-Shan Song of Biology Institute of Hebei Province in Shijiazhuang/China for the kind donation of plasmid pKSSE5.3. This research was supported by the State Basic Science Foundation 973 (Grant No. 2012CB725200, 2012CB725201 and 2011CBA00807). Grants from National Natural Science Foundation of China (Grant No. 31170099 and 30570024) also contributed to this project.

\section{Author details}

'Department of Biological Science and Biotechnology, MOE Key Lab of Bioinformatics and Systems Biology, School of Life Sciences, Tsinghua-Peking Center for Life Sciences, Tsinghua University, Beijing, 100084, China. ${ }^{2}$ Department of Chemistry, University of Melbourne, Parkville, VIC 3052, Australia. ${ }^{3}$ Department of Pharmaceutics and Analytical Chemistry, Faculty of Pharmaceutical Sciences, University of Copenhagen, Copenhagen, Denmark.

${ }^{4}$ Center for Nano and Micro Mechanics, Tsinghua University, Beijing, 100084, China.

Received: 31 March 2012 Accepted: 26 April 2012

Published: 2 May 2012

\section{References}

1. Anderson AJ, Dawes EA: Occurrence, metabolism, metabolic role, and industrial uses of bacterial polyhydroxyalkanoates. Microbiol Rev 1990, 54:450-472

2. Steinbüchel A, Valentin HE: Diversity of bacterial polyhydroxyalkanoic acids. FEMS Microbiol Lett 1995, 128:219-228.

3. Chen $G Q$, Patel MK: Plastics derived from biological sources: present and future: a technical and environmental review. Chemical Rev 2012, 112:2082-2099.

4. Cai L, Tan D, Aibaidula G, Dong XR, Chen JC, Tian WD, Chen GQ: Comparative genomics study of $\mathrm{PHA}$ and ectoine relevant genes from Halomonas sp. TD01 revealed extensive horizontal gene transfer events and co-evolutionary relationships. Microb Cell Fact 2011, 10:88.

5. Martin DP, Williams SF: Medical applications of poly-4-hydroxybutyrate: a strong flexible absorbable biomaterial. Biochem Eng J 2003, 16:97-105.

6. Hazer B, Steinbüchel A: Increased diversification of polyhydroxyalkanoates by modification reactions for industrial and medical applications. Appl Microbiol Biotechnol 2007, 74:1-12.

7. Chen GQ: A microbial polyhydroxyalkanoates (PHA) based bio- and materials industry. Chem Soc Rev 2009, 38:2434-2446.

8. Madison LL, Huisman GW: Metabolic engineering of poly(3hydroxyalkanoates): from DNA to plastic. Microbiol Mol Biol Rev 1999, 63:21-53.

9. Gao X, Chen JC, Wu Q, Chen GQ: Polyhydroxyalkanoates as a source of chemicals, polymers, and biofuels. Curr Opin Biotechnol 2011, 22:768-774

10. Chen GQ, Wu Q: Microbial production and applications of chiral hydroxyalkanoates. Appl Microbiol Biotechnol 2005, 67:592-599.

11. Tripathi L, Wu LP, Chen GQ: Microbial Synthesis of Diblock Copolymer Poly-3-Hydroxybutyrate-block-Poly-3-Hydroxyhexanoate [P(3HB)-b-P $(3 \mathrm{HHx})]$ by a Genome Reduced Pseudomonas putida KT2442. Microb Cell Fact 2012, 11:44

12. Cheng S, Chen GQ, Leski M, Zou B, Wang Y, Wu Q: The effect of D, L- $\beta$ hydroxybutyric acid on cell death and proliferation in L929 cells. Biomaterials 2006, 27:3758-3765.

13. Sun J, Dai ZW, Chen GQ: Oligomers of polyhydroxyalkanoates stimulated calcium ion channels in mammalian cells. Biomaterials 2007, 28:3896-3903.

14. Saito Y, Nakamura S, Hiramitsu M, Doi Y: Microbial Synthesis and Properties of Poly(3-hydroxybutyrate-co-4-hydroxybutyrate). Polym Int 1996, 39:169-174.

15. Mergaert J, Webb A, Anderson C, Wouters A, Swings J: Microbial degradation of poly(3-hydroxybutyrate) and poly(3-hydroxybutyrate-co3-hydroxyvalerate) in soils. Appl Environ Microbiol 1993, 59:3233-3238.

16. Chen $\mathrm{GQ}, \mathrm{Wu} \mathrm{Q}$ : The application of polyhydroxyalkanoates as tissue engineering materials. Biomaterials 2005, 26:6565-6578.

17. Kunioka $M$, Nakamura $Y$, Doi $Y$ : New bacterial copolyesters produced in Alcaligenes eutrophus from organic-acids. Polymer Comm 1988, 29:174-176.

18. Steinbüchel A, Valentin HE, Schönebaum A: Application of recombinant gene technology for production of polyhydroxyalkanoic acids: 
biosynthesis of poly(4-hydroxybutyric acid) homopolyester. J Polymer Environ 1994, 2:67-74.

19. Nakamura S, Doi Y, Scandola M: Microbial synthesis and characterization of poly(3-hydroxybutyrate-co-4-hydroxybutyrate). Macromolecules 1992, 25:4237-4241.

20. Sudesh K, Fukui T, Taguchi K, Iwata T, Doi Y: Improved production of poly (4-hydroxybutyrate) by Comamonas acidovorans and its freeze-fracture morphology. Int J Biol Macromol 1999, 25:79-85.

21. Choi MH, Yoon SC, Lenz RW: Production of poly(3-hydroxybutyric acid-co4-hydroxybutyric acid) and poly(4-hydroxybutyric acid) without subsequent degradation by Hydrogenophaga pseudoflava. Appl Environ Microbiol 1999, 65:1570-1577.

22. Hein S, Sohling B, Gottschalk G, Steinbüchel A: Biosynthesis of poly(4hydroxybutyric acid) by recombinant strains of Escherichia coli. FEMS Microbiol Lett 1997, 153:411-418.

23. Song SS, Hein S, Steinbüchel A: Production of poly(4-hydroxybutyric acid) by fed-batch cultures of recombinant strains of Escherichia coli. Biotechnol Lett 1999, 21:193-197.

24. Lee WH, Azizan MNM, Sudesh K: Effects of culture conditions on the composition of poly(3-hydroxybutyrate-co-4-hydroxybutyrate) synthesized by Comamonas acidovorans. Polymer Degrad Stabil 2004, 84:129-134.

25. Song SS, Ma H, Gao ZX, Jia ZH, Zhang X: Construction of recombinant Escherichia coli strains producing poly (4-hydroxybutyric acid) homopolyester from glucose. Wei Sheng Wu Xue Tong Bao 2005, 45:382-386.

26. Singh M, Patel SKS, Kalia VC: Bacillus subtilis as potential producer for polyhydroxyalkanoates. Microb Cell Fact 2009, 8:38.

27. Valentin HE, Dennis D: Production of poly(3-hydroxybutyrate-co-4hydroxybutyrate) in recombinant Escherichia coli grown on glucose. J Biotechnol 1997, 58:33-38.

28. Li ZJ, Shi ZY, Jian J, Guo YY, Wu Q, Chen GQ: Production of poly(3hydroxybutyrate-co-4-hydroxybutyrate) from unrelated carbon sources by metabolically engineered Escherichia coli. Metab Eng 2010, 12:352-359.

29. Sohling B, Gottschalk G: Molecular analysis of the anaerobic succinate degradation pathway in Clostridium kluyveri. I Bacteriol 1996, 178:871-880.

30. Spyros A, Marchessault RH: Nuclear magnetic-relaxation measurements of poly(4-hydroxybutyrate) and poly(3-hydroxybutyrate-co-4hydroxybutyrate) in the bulk. Macromolecules 1995, 28:6108-6111.

31. Valentin $H E$, Zwingmann $G$, Schonebaum A, Steinbüchel A: Metabolic pathway for biosynthesis of poly(3-hydroxybutyrate-co-4hydroxybutyrate) from 4-hydroxybutyrate by Alcaligenes eutrophus. Eur $J$ Biochem 1995, 227:43-60.

32. Zhang S, Wang ZH, Chen GQ: Microbial polyhydroxyalkanote synthesis repression protein PhaR as an affinity tag for recombinant protein purification. Microb Cell Fact 2010, 9:28.

33. Wang ZH, Ma P, Chen J, Zhang J, Yao YC, Zhang HF, Chen GQ: A heterogeneous two-hybrid system in Escherichia coli based on polyhydroxyalkanoates synthesis regulatory proteins PhaR. Microb Cell Fact 2011, 10:21.

34. Dennis D, Liebig C, Holley T, Thomas KS, Khosla A, Wilson D, Augustine B Preliminary analysis of polyhydroxyalkanoate inclusions using atomic force microscopy. FEMS Microbiol Lett 2003, 226:113-119.

35. Wieczorek R, Pries A, Steinbüchel A, Mayer F: Analysis of a 24-kilodalton protein associated with the polyhydroxyalkanoic acid granules in Alcaligenes eutrophus. J Bacteriol 1995, 177:2425-2435.

36. Potter M, Muller H, Steinbüchel A: Influence of homologous phasins (PhaP) on PHA accumulation and regulation of their expression by the transcriptional repressor PhaR in Ralstonia eutropha H16. Microbiology 2005, 151:825-833.

37. Lux G, Stabenow-Lohbauer U, Langer M, Bozkurt T: Gastroenterology in Germany determination of current status and perspectives. Results of a survey among members of the German Society of Digestive and Metabolic Diseases. Z Gastroenterol 1996, 34:542-548.

38. Potter M, Muller H, Reinecke F, Wieczorek R, Fricke F, Bowien B, Friedrich B, Steinbüchel A: The complex structure of polyhydroxybutyrate (PHB) granules: four orthologous and paralogous phasins occur in Ralstonia eutropha. Microbiology 2004, 150:2301-2311.

39. Potter M, Steinbüchel A: Poly(3-hydroxybutyrate) granule-associated proteins: impacts on poly(3-hydroxybutyrate) synthesis and degradation. Biomacromolecules 2005, 6:552-560.
40. Neumann L, Spinozzi F, Sinibaldi R, Rustichelli F, Potter M, Steinbüchel A: Binding of the major phasin, PhaP1, from Ralstonia eutropha $\mathrm{H} 16$ to poly (3-hydroxybutyrate) granules. J Bacteriol 2008, 190:2911-2919.

41. Kunioka M, Kawaguchi Y, Doi Y: Production of biodegradable copolyesters of 3-hydroxybutyrate and 4-hydroxybutyrate by Alcaligenes eutrophus. Appl Microbiol Biotechnol 1989, 30:569-573.

42. Mitomo H, Hsieh WC, Nishiwaki K, Kasuya K, Doi Y: Poly(3-hydroxybutyrateco-4-hydroxybutyrate) produced by Comamonas acidovorans. Polymer 2001, 42:3455-3461.

43. Pohlmann A, Fricke WF, Reinecke F, Kusian B, Liesegang H, Cramm R, Eitinger T, Ewering C, Potter M, Schwartz E, Strittmatter A, Voss I, Gottschalk G, Steinbüchel A, Friedrich B, Bowien B: Genome sequence of the bioplastic-producing "Knallgas" bacterium Ralstonia eutropha H16. Nat Biotechnol 2006, 24:1257-1262.

44. Kato M, Bao HJ, Kang CK, Fukui T, Doi Y: Production of a novel copolyester of 3-hydroxybutyric acid and medium chain length 3-hydroxyalkanaic acids by Pseudomonas sp 61-3 from sugars. Appl Microbiol Biotechnol 1996, 45:363-370.

45. Chen JY, Liu T, Zheng Z, Chen JC, Chen GQ: Polyhydroxyalkanoate synthases PhaC1 and PhaC2 from Pseudomonas stutzeri 1317 had different substrate specificities. FEMS Microbiol Lett 2004, 234:231-237.

46. Ouyang SP, Luo RC, Chen SS, Liu Q, Chung A, Wu Q, Chen GQ: Production of polyhydroxyalkanoates with high 3-hydroxydodecanoate monomer content by fadB and fadA knockout mutant of Pseudomonas putida KT2442. Biomacromolecules 2007, 8:2504-2511.

47. Gao Y, Kong L, Zhang L, Gong YD, Chen GQ, Zhao NM, Zhang XF: Improvement of mechanical properties of poly(DL-lactide) films by blending of poly(3-hydroxybutyrate-co-3-hydroxyhexanoate). Eur Polymer J 2006, 42:764-775.

48. Luo R, Chen J, Zhang L, Chen G: Polyhydroxyalkanoate copolyesters produced by Ralstonia eutropha PHB - 4 harboring a low-substratespecificity PHA synthase PhaC2Ps from Pseudomonas stutzeri 1317. Biochem Eng J 2006, 32:218-225.

doi:10.1186/1475-2859-11-54

Cite this article as: Zhou et al:: Hyperproduction of poly(4-

hydroxybutyrate) from glucose by recombinant Escherichia coli. Microbial Cell Factories 2012 11:54.

\section{Submit your next manuscript to BioMed Central and take full advantage of:}

- Convenient online submission

- Thorough peer review

- No space constraints or color figure charges

- Immediate publication on acceptance

- Inclusion in PubMed, CAS, Scopus and Google Scholar

- Research which is freely available for redistribution 